\title{
A recent epidemic of Coxsackie virus type A24 acute haemorrhagic conjunctivitis in Singapore
}

\author{
MARGUERITE YIN-MURPHY, BAHARUDDIN-ISHAK, MENG CHEE PHOON, \\ AND VINCENT T K CHOW
}

From the Department of Microbiology, Faculty of Medicine, National University of Singapore, Kent Ridge, Singapore 0511

SUMMARY A recent epidemic of acute conjunctivitis in Singapore showed again the importance of Coxsackie virus type A24 variant as a causative agent of acute haemorrhagic conjunctivitis (AHC). Although the ocular manifestations appeared similar to those described for the 1970 and 1975 outbreaks, a markedly higher rate of respiratory involvements was noted. Not observed in previous epidemics were herpes-like vesicles in the conjunctiva and eyelids of one patient and vesicles in the buccal mucosa and lips of another from whom Coxsackie virus A24 was isolated. The most interesting finding in this study was the isolation of five wild (non-Sabin) poliovirus type 1 strains. Three strains were obtained from conjunctival and two from throat swabs of patients with mild to severe conjunctivitis. It is conceivable that the rare reports of polio-like paralysis or radiculomyelitis accompanying or following AHC in a few Asian countries could be attributed to concurrent infections with a poliovirus and either enterovirus type 70 or Coxsackie virus type A24.

Acute haemorrhagic conjunctivitis (AHC), known also as Apollo II disease, Singapore epidemic conjunctivitis, picornavirus epidemic conjunctivitis, and Bangla Joy conjunctivitis has affected hundreds of millions of people since its appearance in Ghana, Africa, in June 1969, where the first clinical description was given.' The conjunctivitis swept rapidly along the coastal areas of West, East, and North Africa to major cities in the Indian subcontinent, Southeast Asian countries including Japan, and a few European countries in 1970 and 1971.' Large epidemics were confined to the eastern hemisphere, where crowding and unhygienic living conditions contributed to spread of the disease. The first outbreak in the western hemisphere was in the Americas (Brazil) in mid 1981. ${ }^{3}$ At the time of writing the only continent apparently spared this unusually contagious eye affliction was Australia.

Two picornaviruses, namely, a new Coxsackie virus type A24 (CA24) variant isolated for the first time during the 1970 epidemic of acute conjunctivitis in Singapore ${ }^{+7}$ and a new enterovirus-enterovirus type $70(\mathrm{EV} 70)$ isolated from similar epidemics in Morocco, Singapore, and Japan in 1971..$^{x-11}$-are now universally recognised as causative agents of

Correspondence to Dr M Yin-Murphy.
AHC. The first epidemic of CA24 was in August 1970 and the second in June 1975.' EV70 was responsible for epidemics in June 1971, ${ }^{-11}$ August $1978,{ }^{13}$ and July 1980. ${ }^{14}$ In all instances outbreaks caused by CA24 variant were more explosive and extensive than those caused by EV70. However, the types of conjunctivitis caused by these two picornaviruses are indistinguisable.

The common features of $\mathrm{AHC}$ are mild to severe follicular conjunctivitis, subconjunctival haemorrhage in severe cases, which gave it the name 'acute haemorrhagic conjunctivitis,' and fine pinpoint epithelial keratitis. Punctate subepithelial keratitis and corneal erosion are rare. The conjunctivitis generally resolved within one to two weeks of onset without sequalae. Respiratory and gastrointestinal disturbances accompany some cases. Secondary bacterial infections are common. ${ }^{+\times}$Rare cases of neurological complications including radiculomyelitis, palatal paresis, and Bell's palsy accompanying or following conjunctivitis caused by EV70 have been reported from India, Taiwan, Thailand, and America. 1:-2n

We present here the clinical and laboratory findings of the March-June 1985 epidemic of acute conjunctivitis in Singapore. For the 12-week period a total of 29920 patients were treated by Government 
clinics (Tan $\mathrm{J} \mathrm{L}$ personal communication). ' This is the third major outbreak of AHC caused by the CA24 variant in Singapore.

\section{Materials and methods}

Clinical investigation. A random study was carried out on 65 patients who attended the Government Clementi Polyclinic. The patients ranged from 3 to 55 years old. All these patients sought treatment within the first three days of the onset of conjunctivitis with the exception of three, one of whom was examined on the fourth day, one on the fifth, and one on the seventh day. Conjunctival swabs, tears, throat swabs, and blood where agreed to by the patients were collected and tested by the methods described $512 \geq 1$

Virus isolation and identification. Conjunctival and throat swabs were processed and inoculated into HeLa cell cultures grown in microtitration plates, and virus isolates were identified by a microneutralisation test with monkey antisera to CA24 (Singapore Epidemic Conjunctivitis 1970) virus and EV70 (Singapore Epidemic Conjunctivitis 1971) as described. ${ }^{21} 22$ Tear samples were examined for virus particles by electron microscopy."

Serology. Each sample of serum was tested for antibody to both CA24 virus and EV70 by a microneutralisation test. ${ }^{22}$

\section{Results}

Table 1 presents an analysis of the 65 patients studied. More females than males were affected, with a preponderance in the 5 to 14 and 15-24 year age groups.

Bilateral conjunctivitis was present in $43(66 \cdot 2 \%)$, lid swelling in $45(69 \cdot 2 \%)$, mild conjunctivitis in 29 $(44.6 \%)$, severe conjunctivitis in $36(55 \cdot 4 \%)$, and purulent discharge in $12(18.5 \%)$. Subconjunctival haemorrhage was seen in $14(21.5 \%)$ patients, one of whom had corneal oedema. Herpes-like vesicles were seen in the conjunctiva and skin of the eyelids of one patient.

Upper respiratory tract infections were seen in 54 $(83.0 \%)$ cases, and in $1(1.5 \%)$ patient vesicular lesions in the buccal mucosa and lips. Twenty-two $(33.8 \%)$ patients complained of headaches, 7 $(10 \cdot 8 \%)$ of gastrointestinal disturbances, and 1 $(1.5 \%)$ of anorexia with myalgia.

From 61 conjunctival swabs 51 strains of CA24 virus and three strains of poliovirus type 1 were isolated. Forty-nine strains of CA24 virus, and two of poliovirus type 1 were recovered from 63 throat swabs. Seven of 11 tear samples $(63.6 \%)$ contained virus particles resembling picornaviruses.
Table 1 Analysis of 65 cases of acute conjunctivitis (1985)

\begin{tabular}{lcc}
\hline & Number of cases & Percentage \\
\hline Agc $0-4$ & 2 & $3 \cdot 0$ \\
$5-14$ & 23 & $35 \cdot 4$ \\
$15-24$ & 17 & $26 \cdot 2$ \\
$25-34$ & 11 & $16 \cdot 9$ \\
$35-44$ & 8 & $12 \cdot 3$ \\
$45-54$ & 3 & $4 \cdot 6$ \\
$55-64$ & 1 & $1 \cdot 5$ \\
Malc & 26 & $40 \cdot()$ \\
Fcmalc & 39 & $60 \cdot 1$ \\
Latcrality & & \\
Bilateral & 43 & $66 \cdot 2$ \\
Unilateral & 22 & $33 \cdot 9$ \\
Conjunctivitis & & \\
Mild & 29 & $44 \cdot 6$ \\
Scverc & 36 & $55 \cdot 4$ \\
Subconjunctival hacmorrhage & 14 & $21 \cdot 5$ \\
Corncal ocdema & 1 & $1 \cdot 5$ \\
Vesicles in conjunctiva and cyc lid & 1 & $1 \cdot 5$ \\
Lid swelling & 45 & $69 \cdot 2$ \\
Purulent dischargc & 12 & $18 \cdot 5$ \\
Coryza & 24 & $36 \cdot 9$ \\
Pharyngitis & 54 & $83 \cdot 0$ \\
Tonsillitis & 2 & $3 \cdot 1$ \\
Cough & 7 & $10 \cdot 8$ \\
Vesicles in buccal mucosa and lips & 1 & $1 \cdot 5$ \\
Headache & 22 & $33 \cdot 8$ \\
Anorexia and myalgia & 1 & $1 \cdot 5$ \\
Gastrointestinal disturbances & 7 & $10 \cdot 8$ \\
\hline
\end{tabular}

Only one of 16 patients from the study series donated a second blood sample. A four-fold neutralising antibody (NA) rise from 20 to 80 to CA24 virus was registered between the acute and convalescent sera in this patient. Fourteen of 16 acute sera $(87.5 \%)$ had no $(<20)$ NA to CA24 virus, while the remaining two had titres of 20 and 80 respectively. Eight of these 16 acute sera had no $(<20)$ NA to E70, five a titre of 20 , two a titre of 40 , and one a titre of 80 .

Twenty-eight patients had had previous attack of the conjunctivitis: nine in 1984, eight in 1983, two in 1982 , three in 1980, and one each in 1978, 1975, 1973, 1970 , and 1981/1982; and one patient complained of yearly episodes of conjunctivitis.

\section{Discussion}

The third extensive epidemic of acute conjunctivitis caused by CA24 in April-June 1985 resembled the previous two epidemics in August 1970 and June 1975. The manifestations of conjunctivitis were similar to those described. ${ }^{+\times 12}$ The striking features of severe acute haemorrhagic conjunctivitis are shown in Fig. 1 to 3 taken of a 12-year-old boy one week after the onset of conjunctivitis. Blood stained tears, severe ecchymoses and subconjunctival haemorrhage, follicular hypertrophy of palpebral conjunctiva, and ptosis are seen. 


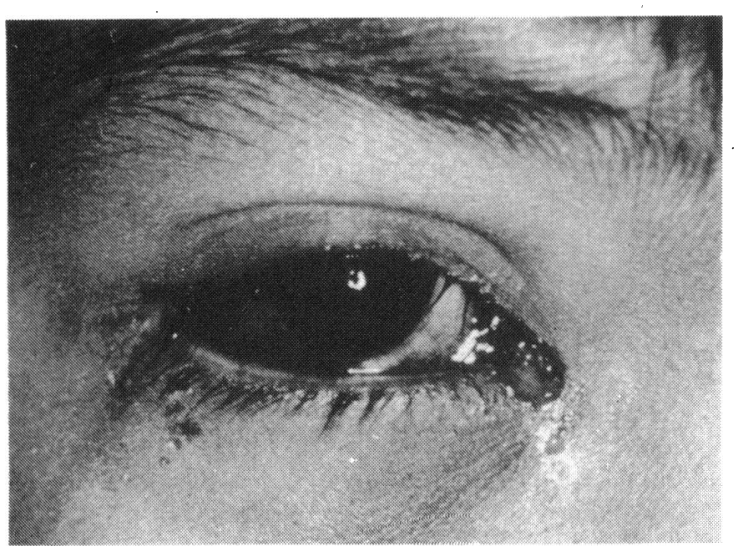

Fig. 1 Blood stained tear discharge, severe ecchymoses, subconjunctival haemorrhage, and ptosis.

Most patients $(83 \%)$ had respiratory tract infections and many $(33.8 \%)$ complained of headaches. Not observed before was the presence of herpes-like vesicular lesions in the conjunctiva and skin of the eyelids of one patient and in the buccal mucosa and lips of another from whom CA24 virus was isolated.

Interestingly, of 54 isolates obtained from 61 conjunctival swabs 51 were CA24 virus and three poliovirus type 1 . Forty-nine of 51 isolates from 63 throat swabs were of CA24 virus and two of poliovirus type 1 . Of the five poliovirus isolates two were from the throat of a 9-year-old boy and an 8-year-old girl whose conjunctival swabs yielded CA24 virus. One came from the conjunctival swab of a 30 -year-old woman whose throat swab yielded a CA24 virus, and the remaining two poliovirus strains were from the conjunctival swabs of women age 27 and 30 years whose throat swabs were virus negative. Intratypic serodifferentiation by the enzyme-linked immunosorbent assay with strain specific antisera showed

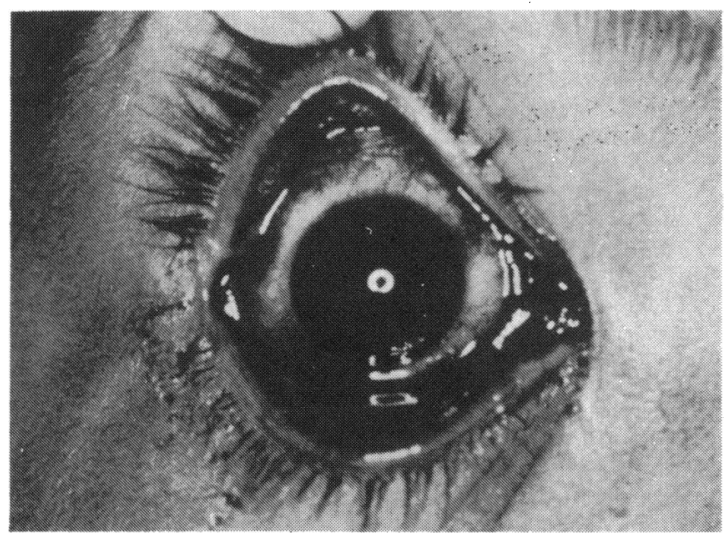

Fig. 3 Conjunctival oedema, diffuse subconjunctival haemorrhage. No membrane formation, and cornea is clear.

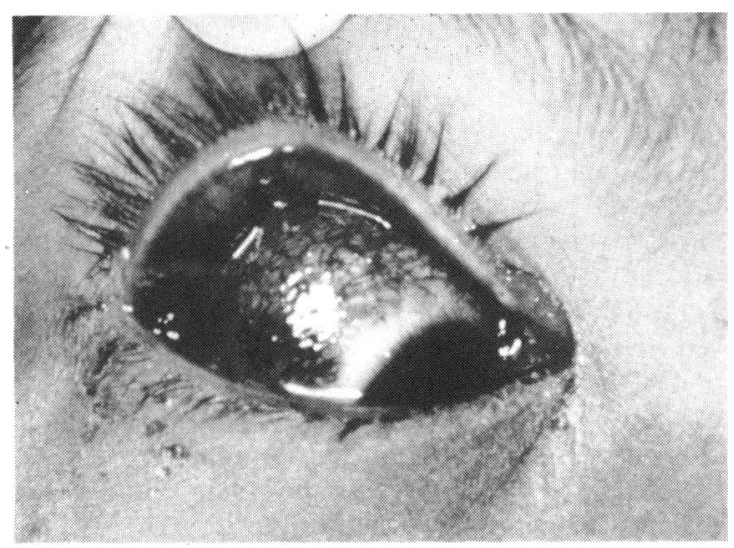

Fig. 2 Follicular hypertrophy of palpebral conjunctiva and blotches of subconjunctival haemorrhage.

these poliovirus type 1 strains to be wild (non-Sabin) poliovirus strains.

This is not the first time that poliovirus strains have been isolated from the conjunctiva of patients during epidemics of acute haemorrhagic conjunctivitis. Two virus strains from conjunctival swabs obtained during the 1971 and one from the 1975 conjunctivitis epidemics in Calcutta sent to us by Professor J K Sarkar, Department of Virology, School of Tropical Medicine, were identified as poliovirus type 1 . This finding was confirmed by Dr R Kono, Central Virus Diagnostic Laboratory, Tokyo, Japan, who received duplicate aliquots of these isolates. Furthermore, an isolate from a conjunctival swab sampled during the 1984 epidemic in Malaysia caused by EV70 received from Dr S K Tan, Institute of Medical Research, Kuala Lumpur, was identified as poliovirus type 2 . The poliovirus type 1 and poliovirus type 2 strains were also forwarded by us to Dr Van Wezel, and they were typed as non-Sabin poliovirus type 1 and type 2 respectively. In all these instances the laboratories were not involved in poliovirus investigation during the AHC epidemics.

It is conceivable that rare cases of polio-like paralysis following AHC reported in a few Asian countries may be due to concurrent infections with a poliovirus and an EV70 or CA24 virus.

It is not surprising that only two of 16 acute sera contained neutralising antibody to CA24 in view of the fact that the last epidemic of CA24 AHC occurred in 1975. The higher number (eight out of 16) seropositive for EV70 could be accounted for by the more frequent and recent E70 outbreaks in 1971, 1978,1980 , and the last quarter of 1983 to beginning of 1984. Sporadic cases of EV70 were observed together with CA24, adenovirus types $3,7,8,11$, and 19 during interepidemic periods.

Rapid and early diagnosis of AHC can be achieved 
by electron microscopy if the infecting agents are sufficiently abundant in tears during the early onset of conjunctivitis. Seven of 11 tear samples contained picornavirus-like particles. CA24 cannot, however, be distinguished from E70 morphologically, but these AHC viruses can be differentiated from adenovirus serotypes, which give rise to conjunctivitis clinically similar to that caused by CA24 and E70. ${ }^{2 .-25}$ Although isolation in tissue cell cultures is more sensitive than electron microscopy for the detection of CA24, it requires several days for cytopathogenic effects to appear, and in the case of E70 several tissue culture passages are required. A reliable isolation system for E70 has yet to be found, and often diagnosis depends on serological tests.

Twenty-eight of 65 patients recalled a previous attack of conjunctivitis, 18 within the past two years, including one who complained of yearly attack for many years.

The frequent involvement of the CA24 variant in epidemics of acute haemorrhagic conjunctivitis and the extremely contagious nature of this eye infection is clearly shown by the explosive and extensive outbreaks in Singapore, ${ }^{+6}$ Malaysia, and Hong Kong in $1970 ;{ }^{5}$ Singapore, ${ }^{12}$ Hong Kong, ${ }^{26}$ Bombay and Poona, ${ }^{27}$ New Delhi, ${ }^{28}$ Bangladesh (Thongcharoen $P$, personal communication), Sri Lanka, ${ }^{24}$ Brunei, ${ }^{, 4}$ Bangkok ${ }^{31}$ and Vellore ${ }^{32}$ in 1975; Malaysia ${ }^{33}$ and Sri Lanka (Vitaran T, personal communication) in 1978; Poona, (Pavri K M, personal communication), Bombay, ${ }^{34}$ and Vellore in 1979. ${ }^{35}$ Our investigation of the current epidemics of AHC in Brunei which started in August and in Malaysia in December 1985 shows they also are of CA24 virus aetiology.

The epidemicity and pandemicity of enterovirus conjunctivitis is said to be parallelled by only one other viral disease-influenza.

We thank Dr Ng Yook Kim, Medical Director of Outpaticnt Services, Primary Health Care Services, Ministry of Health, Dr Lim Gek Nec, Registrar of Maternal Child Health Services, and Madam Chew Kim Boon, Nursing Officer of the Clementi Polyclinic for having made it possible for us to carry out this study. We are also grateful to Dr A L van Wezel, Rijks Instituut voor Volksgezonheid en Milicuhygiene, The Netherlands, for intratypic serodifferentiation of the poliovirus strains, to Mrs Josephine Howe for assistance in photography, and to the Singapore Turf Club for financial support.

\section{References}

1 Chatterjec S, Quarcoopome CO, Apenteng A. An epidemic of acute conjunctivitis in Ghana. Ghana Med J 1970; 9: 9-11.

2 Yin-Murphy M. Acutc hacmorrhagic conjunctivitis. Prog Med Virol 1984; 29: 23-44.

3 WHO Weekly Epidemiol Rec 1981; 56: 293-4.

$4 \mathrm{Lim} \mathrm{KH}$, Yin-Murphy M. An epidemic of conjunctivitis in Singaporc in 1970. Singapore Med J 1971; 12: 247-9.

5 Yin-Murphy M. An cpidemic of picornavirus conjunctivitis in Singaporc. Southeast Asian J Trop Med Public Health 1972; 3: 303-9.
6 Yin-Murphy M, Lim KH. Pictornavirus epidemic conjunctivitis in Singaporc. Lancet 1972; ii: 587-9.

7 Mirkovic BR, Schmidt NJ, Yin-Murphy M, Melnick JL. Enterovirus etiology of the 1970) Singapore epidemic of acutc conjunctivitis. Intervirology 1974; 4: 119-27.

$8 \mathrm{Lim} \mathrm{KH}$. Yin-Murphy M. Epidemic conjunctivitis in Singapore in 1970) and 1971. Singapore Med J 1973; 14: 86-9.

9 Yin-Murphy $M$. Viruses of acutc hacmorrhagic conjunctivitis. Lancet 1973; i: 545-6.

10 Yin-Murphy M. The picornaviruses of acute hacmorrhagic conjunctivitis. A comparative study. Southeast Asian J Trop Med Public Health 1973; 4: 305-10.

11 Mirkovic RR, Kono R, Yin-Murphy M, Sohicr R, Schmidt NJ, Melnick JL. Entcroviruses type 70 - the etiologic agent of pandemic acute hacmorrhagic conjunctivitis. Bull WHO 1973; 49: 341-6.

12 Yin-Murphy M, Lim KH, Ho YM. A Coxsackicvirus type A24 cpidemic of acutc conjunctivitis. Southeast Asian J Trop Med Public Health 1976; 7: 1-5.

13 Ministry of Health Annual Report. Department of Pathology. General Hospital, Singapore. 1978; 7.

14 Goh KT, Doraisingham S, Yin-Murphy M. An cpidemic of acutc conjunctivitis caused by entcrovirus 70) in Singapore in 1980. Southeast Asian J Trop Med Public Health 1981; 12: 473-80.

15 Wadia NH, Irani PF, Katrak SM. Lumbrosacral radiculomyclitis associated with pandemic acute hacmorrhagic conjunctivitis. Lancet 1973; i: $350-2$.

16 Green IJ, Hung TP, Sung, SM. Neurological complications with clevated antibody titer after acutc hacmorrhagic conjunctivitis. Am J Ophthalmol 1975; 80: 832-4.

17 Kono, R, Miyamura K, Tajiri E, et al. Virological and scrological studics of ncurological complications of acute hacmorrhagic conjunctivitis in Thailand. J Infect Dis 1977; 135: 706-13.

18 John TJ, Christopher S, Abraham J. Ncurological manifestation of acutc hacmorrhagic conjunctivitis duc to E7(). Lancet 1981; ii: 1283-4

19 Bharucha EP, Mondkar VP, Kulkarni SA. Post-conjunctival mycloradiculopathy. Neurology (India) 1982; 22: 79-82.

20 Sklar VEF, Patriarca PA, Onorato IM, et al. Clinical findings and results of treatment in an outbreak of acute hacmorrhagic conjunctivitis in Southern Florida. Am J Ophthalmol 1983; 95: 45-54.

21 Yin-Murphy M. Simple tests for the diagnosis of picornavirus epidemic conjunctivitis (acutc hacmorrhagic conjunctivitis). Bull WHO 1976; 54: 675-9.

22 Yin-Murphy M, Abdul Rahim N, Pnoon MC, BaharuddinIshak, Howc J. Early diagnosis of acutc hacmorrhagic conjunctivitis with tcar specimens. Bull WHO 1985; 63: 705-9.

23 Yin-Murphy M, Lim KH, Chua PH. Adenovirus type 11 epidemic conjunctivitis. Southeast Asian J Trop Med Public Health 1974; 5: 333-41.

24 Tai FH, Lin HM, Chu S, Wci HY, Hicrholzer JC. A ncw form of acutc conjunctivitis in Taiwan. A simultancous outbreak of adcnovirus type 11 and acutc hacmorrhagic conjunctivitis virus infection. Clin J Microbiol 1974; 7: 79-88.

25 Taylor JW, Chandler JW, Cooncy MK. Acutc hacmorrhagic conjunctivitis associated with adenovirus typc 19. $N$ Engl J Med 1975; 292: 978-9.

26 Chang WK, Liu KC, Foo TC, Lam MW, Chan CF. Acute hacmorrhagic conjunctivitis in Hong Kong 1971-1975. Southeast Asian J Trop Med Public Health 1977; 8: 1-6.

27 Gogate SS, Gupta NP, Anantanarayan TR, Wagh UV, Bancrjec $\mathrm{K}$, Ilkal MA. Laboratory investigations of an epidemic of acute hacmorrhagic conjunctivitis in Bombay and Poona in 1975. J Indian Med Assoc 1978; 70: 34-7.

28 Arora RR, Gupta JP, Sabestian M. Epidemiological and virological study of a conjunctivitis epidemic in New Delhi in 1975. Indian J Med Res 1977; 66: 6-13.

29 Higgins PG, Chapman TED. Coxsackicvirus A24 and acute hacmorrhagic conjunctivitis in Sri Lanka. Lancet 1977; i: 361. 
30 Bharin MA, Joshi ND, Yin-Murphy M. A coxsackievirus type A24 epidemic conjunctivitis in Brunei. Southeast Asian J Trop Med Public Health 1976; 7: 355-8.

31 Thongcharoen P, Wasi C, Pimolpan V, Panpatna P. Etiologic studies on acutc haemorrhagic conjunctivitis in Thailand 19711975. J Med Assoc Thailand 1978; 61: 195-201.

32 Christopher S, John TJ, Charles V, Ray S. Coxsackicvirus A24 variant EH24/70 and E70 in an epidemic of acute haemorrhagic conjunctivitis. A preliminary report. Indian J Med Res 1977; 65: 593-5.
33 Tan DSK, Yin-Murphy M, Kandiah S. An outbreak of acutc conjunctivitis caused by coxsackicvirus A24 in Kuala Lumpur, Malaysia, 1978. Southeast Asian J Trop Med Public Health 1980; 11: $24-7$.

34 Gogatc SS, Padbidri VS. Studics on an outbreak of conjunctivitis in Bombay 1979. Indian J Pathol Microbiol 1981; 24: 257-9.

35 John JT. An cpidemic of acutc hacmorrhagic conjunctivitis duc to coxsackicvirus A24. J Infect Dis 1982; 146: 16-9.

Accepted for publication 24 January 1986. 